\title{
PAPER
}

Cite this: Phys. Chem. Chem. Phys., 2013, 15, 4329

Received 10th December 2012, Accepted 29th January 2013

DOI: $10.1039 / \mathrm{c} 3 \mathrm{cp} 44431 \mathrm{~g}$

www.rsc.org/pccp

\section{Electrocatalytic performance of fuel cell reactions at low catalyst loading and high mass transport}

\author{
Christopher M. Zalitis, Denis Kramer† and Anthony R. Kucernak*
}

\begin{abstract}
An alternative approach to the rotating disk electrode (RDE) for characterising fuel cell electrocatalysts is presented. The approach combines high mass transport with a flat, uniform, and homogeneous catalyst deposition process, well suited for studying intrinsic catalyst properties at realistic operating conditions of a polymer electrolyte fuel cell (PEFC). Uniform catalyst layers were produced with loadings as low as $0.16 \mu \mathrm{g}_{\mathrm{Pt}} \mathrm{cm}^{-2}$ and thicknesses as low as $200 \mathrm{~nm}$. Such ultra thin catalyst layers are considered advantageous to minimize internal resistances and mass transport limitations. Geometric current densities as high as $5.7 \mathrm{~A} \mathrm{~cm}^{-2}$ Geo were experimentally achieved at a loading of $10.15 \mu \mathrm{g}_{\mathrm{Pt}} \mathrm{cm}^{-2}$ for the hydrogen oxidation reaction (HOR) at room temperature, which is three orders of magnitude higher than current densities achievable with the RDE. Modelling of the associated diffusion field suggests that such high performance is enabled by fast lateral diffusion within the electrode. The electrodes operate over a wide potential range with insignificant mass transport losses, allowing the study of the ORR at high overpotentials. Electrodes produced a specific current density of $31 \pm 9 \mathrm{~mA} \mathrm{~cm}^{-2}$ spec at a potential of $0.65 \mathrm{~V}$ vs. RHE for the oxygen reduction reaction (ORR) and $600 \pm 60 \mathrm{~mA} \mathrm{~cm}^{-2}$ spec for the peak potential of the HOR. The mass activity of a commercial $60 \mathrm{wt} \% \mathrm{Pt} / \mathrm{C}$ catalyst towards the ORR was found to exceed a range of literature PEFC mass activities across the entire potential range. The HOR also revealed fine structure in the limiting current range and an asymptotic current decay for potentials above $0.36 \mathrm{~V}$. These characteristics are not visible with techniques limited by mass transport in aqueous media such as the RDE.
\end{abstract}

\section{Introduction}

Understanding the kinetics of the oxygen reduction reaction (ORR) and hydrogen oxidation reaction (HOR) on platinum nano-particles is vital for polymer electrolyte fuel cell (PEFC) development. Each platinum nano-particle within the electrode should have optimal proton access, gas access and an electronic path to study intrinsic electrocatalytic properties of the catalyst. These three criteria should be maintained throughout the working conditions (e.g., temperature, humidity and potential). If a reaction site is starved for any of the three, its activity will be reduced, which skews the average activity and introduces an error. It is paramount to minimize the number of under performing catalyst sites to determine intrinsic catalyst properties. Ideally, the catalyst layer should be made as thin as possible. Thus, all the catalyst particles will be close to the

Imperial College London, Department of Chemistry, London, SW7 2AZ, UK.

E-mail: anthony@imperial.ac.uk; Tel: +44 (0)20 75945831

$\dagger$ Present address: University of Southampton, Facility of Engineering and Environment, Southampton, Hants, SO17, UK. perfluorosulfonic acid (PFSA) membrane for ionic access and close to the gas diffusion layer (GDL) for gas access and an electronic path, removing internal limitations. Mass transport limitations lead to concentration polarization across thick electrodes, ${ }^{1-3}$ limiting the active thickness to about $5 \mu \mathrm{m}$ at high current densities, regardless of how thick the catalyst layer is. ${ }^{1}$

The majority of ORR and HOR fundamental research is conducted using the RDE. ${ }^{2-6}$ While the RDE is a powerful technique, being submerged in the electrolyte limits the achievable current densities due to insufficient mass transport of reactants to the surface, even if thin catalyst layers are deposited onto the inert disk of the RDE (usually glassy carbon) at low catalyst loadings, $7-28 \mu \mathrm{g}_{\mathrm{Pt}} \mathrm{cm}^{-2}$. ${ }^{6}$ In aqueous electrolytes such as $\mathrm{H}_{2} \mathrm{SO}_{4}$ or $\mathrm{HClO}_{4}$, the concentration and diffusion coefficient of oxygen and hydrogen are very low, implying considerably lower limiting currents than expected for a PEFC. Even at the rotation rate limit of $\sim 10 \mathrm{k} \mathrm{rpm}$, the limiting mass transport currents densities are only 14 and $6 \mathrm{~mA} \mathrm{~cm}^{-2}$ Geo for the ORR and HOR, respectively. ${ }^{7}$ PEFCs operating with pure hydrogen and oxygen can have current densities up to three orders of magnitude higher than this. Therefore, data from the RDE is 
extrapolated to PEFC current densities, which can introduce significant errors. ${ }^{8,9}$

This can be partially mitigated by reducing the catalyst loading further, which reduces the kinetic current, allowing measurements to be taken at higher overpotentials before reaching the limiting mass transport current density. Sun et $a l^{3}$ applied this strategy to study the HOR on a RDE with catalyst loadings in the range of $0.008-1.2 \mu \mathrm{g}_{\mathrm{Pt}} \mathrm{cm}^{-2}$. However, the mass transport limitation was still reached quickly, and they found depositing ultra thin layers challenging, as the catalyst would deposit in a non-uniform manner. The nonuniformity was most probably caused by capillary effects of the solvent in the catalyst ink, pulling catalyst to the edges of the drop as it dries. ${ }^{10}$ Therefore, they reduced catalyst loadings by adding uncatalyzed carbon, creating a thicker layer of equivalent thickness to a higher catalyst loading.

Measuring the catalytic activity within a PEFC would be the most appropriate method. A number of groups have gained fundamental insight into the ORR and HOR using fuel cell apparatus. ${ }^{11-15}$ However, these studies are limited by the fuel cell design and operation, proving intricate and time consuming to optimize for fundamental studies. ${ }^{2}$ Several potential sources of error need to be considered. Firstly, hydrogen crossover results in a parasitic current on the order of $\mathrm{mA} \mathrm{cm}{ }^{-2}$ Geo that has to be removed on analysis, ${ }^{13}$ because it skews the ORR data; this crossover increases with temperature and pressure, adding further complexity. ${ }^{16}$ Secondly, a two electrode configuration is typically used, causing the measured signal to be a contribution of both electrodes. A reliable three electrode setup, although highly desirable for kinetic studies, is difficult to realize in an operating PEFC. An inappropriate perimeter-placed reference is sometimes used. ${ }^{17,18}$ But most commonly, the ORR characteristics are simply assumed to dominate the signal to justify the use of a two-electrode setup, which appears reasonable given the higher exchange current density of the HOR. However, Kuhn et al. ${ }^{19}$ separated the contributions with a pseudo reference electrode sandwiched between the electrodes and found that the HOR impedance was not negligible under their conditions, but of the same order of magnitude across the entire cell impedance range. Lastly, it is challenging to minimize concentration gradients of reactants, products and water distribution across a flow field of a PEFC, generally from the inlet to the outlet $^{7}$ and also under channel and land. ${ }^{20,21}$ Therefore, the current distribution across the electrode has an element of inhomogeneity. All these points can distort results if not carefully accounted for. Ideally, a technique is needed which has the simplicity of the RDE while avoiding mass transport limitations at high overpotentials to obtain a closer comparison to fuel cell data at high current densities.

Floating a porous gas diffusion electrode on aqueous electrolyte provides this alternative approach. The method is able to use a three electrode configuration and supply the reactant gas to the surface sites of the catalyst from behind the catalyst layer. The gaseous diffusion leads to a three order of magnitude increase in mass transport of reactant gases to the catalyst layer. In the past, such electrodes have achieved $\sim 3 \mathrm{~A} \mathrm{~cm}^{-2}$ Geo at a platinum loading of $55 \mathrm{mg}_{\mathrm{Pt}} \mathrm{cm}^{-2}$ for the HOR. ${ }^{22}$ In this way, the kinetics of the ORR and HOR can be measured over a much wider potential window which includes the typical cell potential window of PEFC operation (0.6-0.8 V vs. RHE for the cathode). Extensive experimental studies of these 'floating electrodes' for the phosphoric acid fuel cell have been conducted in the 1960 's-1980's ${ }^{22-25}$ and were augmented with theoretically models. ${ }^{26-28}$

More recently, the floating electrode has been adapted for PEFC studies. ${ }^{29,30}$ Antolini et $a l .{ }^{29}$ fabricated electrodes to study geometry effects such as PFSA content, an important parameter of PEFC electrodes. This catalyst layer was $40 \mu \mathrm{m}$ thick, with a loading of $200 \mu \mathrm{g}_{\mathrm{Pt}} \mathrm{cm}^{-2}$; not optimized for intrinsic catalyst property studies. Later, Chen et al..$^{30}$ sputtered a $3 \mathrm{~nm}$ layer of platinum (roughness factor of 1.45) onto the surface of a substrate to achieve an ultra thin catalyst layer for temperature dependence studies.

The next logical step is to develop a method for depositing catalyst layers using $\mathrm{Pt} / \mathrm{C}$, which is the standard for PEFC electrodes, and geared towards studying intrinsic activity. Fig. 1 depicts what might be thought of as an ideal situation to accurately study the catalytic properties of a $\mathrm{Pt} / \mathrm{C}$ particle. The particle rests on a conductive support, directly over a hydrophobic pore. The pore acts as a direct pathway for the reactants and products to flow freely to and from the catalyst particle in the gas phase, while the front of the catalyst particles is in contact with the aqueous electrolyte. This kind of geometry would allow intrinsic performance of a catalyst across the entire fuel cell operating range.

In this paper, a method is described to produce ultra thin, uniform catalyst layers. The catalyst was deposited via vacuum filtration onto a porous substrate, which we refer to as the vacuum filtered catalyst (VFC) method, able to deposit any catalyst provided it can be trapped upon filtration. These ultra low catalyst loadings were achieved without the need to add uncatalyzed carbon, achieving layers down to $200 \mathrm{~nm}$ thick for $0.16 \mu \mathrm{g}_{\mathrm{Pt}} \mathrm{cm}^{-2}$. The small amount of catalyst needed makes it an ideal technique to measure novel catalysts, produced on a small scale. Uniform deposition was achieved by eliminating the evaporation step from the catalyst deposition. Evaporation commonly

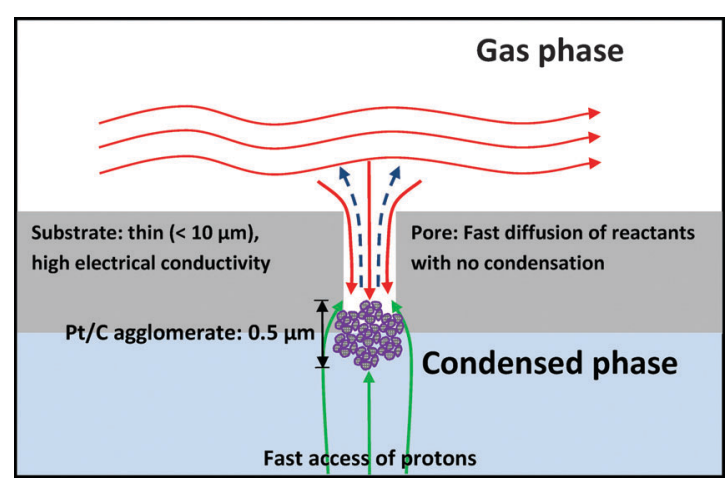

Fig. 1 Diagram of a catalyst particle in an optimised position for electrocatalytic activity. 
leads to inhomogeneity, because strong capillary effects pull catalyst to the edges of an evaporating drop. ${ }^{10}$ The porous substrate is a gold coated polycarbonate track etched (PCTE) membrane. Such porous substrates have already been successfully incorporated into glucose fuel cells by Kloke et al., ${ }^{31}$ although their gold-coated PCTE electrode was operated in neutral $\mathrm{pH}$ and completely submerged in electrolyte. The PCTE membrane acts as a GDL in our configuration, which was operated at much higher mass transport rates and in acidic conditions.

Initial results of the intrinsic catalytic activity of platinum for the fuel cell reactions (ORR and HOR) are presented and the effectiveness of this approach discussed. A model for diffusion through open pores and a flooded catalyst layer is presented and assessed by comparing it to the performance of our system.

\section{Experimental}

\section{Cleaning procedure for the equipment and materials}

Cleanliness was an important factor to achieve optimum electrocatalytic performance of a catalyst layer, especially with these ultra low loading catalyst layers, as such small amounts of catalyst will attain an equilibrium coverage of contaminants much faster than electrodes with typical loadings of platinum. With this in mind, all glassware was soaked in acidified potassium permanganate for $8 \mathrm{~h}$, rinsed with acidified hydrogen peroxide and then rinsed at least six times with ultra pure water before use. Gas purities of $\geq 5.8 \mathrm{~N}$ (Air Products) were utilized with $6 \mathrm{~N}$ rated regulators (GCE DruVa). Electrolytes were prepared using "Aristar" grade acids (BDH Aristar grade sulfuric acid and perchloric acid from VWR) and ultra pure water (Millipore Milli-Q, $18.2 \mathrm{M} \Omega \mathrm{cm}$ ). The PCTE membranes (Sterlitech, PCTF0447100) were washed in a Soxhlet extractor, with propan-2-ol, followed by ultra pure water under reflux for $8 \mathrm{~h}$ each. After this cleaning procedure, platinum CVs showed a decrease of hydrogen adsorption charge of $5 \%$ over a period of 7 minutes utilizing a potential scan window of $0.05-0.3 \mathrm{~V} v$ s. RHE. ${ }^{32}$

\section{Preparation of the porous substrate and catalyst spot}

The substrate for the catalyst support was made of a porous PCTE membrane. The commercially available porous PCTE membrane is an inert substrate with good resistance to most acids including sulfuric acid and perchloric acid, remains durable down to $6 \mu \mathrm{m}$ thicknesses and has a glass transition temperature of $150{ }^{\circ} \mathrm{C}$, allowing for standard hot pressing conditions $\left(140{ }^{\circ} \mathrm{C}\right)$ to be used in MEA preparation. ${ }^{33}$ Porosity is created by the track etching technique to produce parallel cylindrical pores with controlled sizes and densities with a tortuosity $(\tau)$ of 1 . The membranes used in this study had $10^{8}$ pores $\mathrm{cm}^{-2}$ and a pore size of $400 \mathrm{~nm}$ giving a porosity of 0.125 . This membrane was coated with a $100 \mathrm{~nm}$ gold layer by sputter deposition (Emitech K575X) to act as a current collector. The electrodes were weighed before and after the gold sputter coating to determine the gold loading and from that, the deposition thickness was calculated.
The catalyst ink consisted of $60 \% \mathrm{Pt} / \mathrm{C}$ catalyst (Alfa Aesar, HiSPEC 9100, $50 \mathrm{mg}$ ), butyl acetate (Sigma, anhydrous grade, $950 \mathrm{mg}$ ), propan-2-ol (VWR, Normapur analytical reagent, $570 \mathrm{mg}$ ) and a PFSA solution (DuPont DE521 Nafion solution, $5 \mathrm{wt} \%$, $380 \mathrm{mg}$ ). First, the propan-2-ol, butyl acetate and Pt/C catalyst were sonicated (Powersonic P230D) for 10 minutes to disperse the catalyst. After, the PFSA solution was added and the mixture sonicated for a further two hours. A particle size analyzer (Coulter, LS230) applying dynamic light scattering was utilized to measure the particle size of the ink solution. The solvents are known to cause the PFSA to form colloids, improving ionic percolation. ${ }^{34,35}$ In this way, the PFSA should coagulate around the pre-dispersed catalyst to create a homogeneous catalyst ink. As the PFSA coagulates around the catalyst particles, they should be retained with the catalyst upon filtration and not be washed through with the filtrate, complementing the VFC method.

Catalyst spots of $2 \mathrm{~mm}$ diameter were produced using a $2 \mathrm{~mm}$ diameter mask fitted over the filter. A volume of catalyst ink to produce the required loading was diluted to $2 \mathrm{ml}$ with a $50: 50$ mix of butyl acetate and propan-2-ol. This volume was required to assure a uniform distribution of catalyst. During filtration, some of the smaller catalyst particles were sucked through the PCTE membrane. Fig. 2 shows a comparison of the expected catalyst loadings in the ink before deposition and the catalyst loadings which were electrochemically active on the surface after deposition. As can be seen for the ultra low loadings, considerably more catalyst was lost (up to 85\%). It is to be expected that the catalyst particles below the PCTE membrane's pore diameter $(400 \mathrm{~nm})$ would be lost during deposition. The inset in Fig. 2 shows a particle size analysis of the catalyst ink. There are three particle size distributions of $0.05,0.2$ and $0.5 \mu \mathrm{m}$ peak diameters, with a volume fraction of $0.79,0.07$ and 0.14 , respectively. The $0.05 \mu \mathrm{m}$ fraction corresponds to primary carbon particles, verified in the SEM image in Fig. 4C). The particle distributions of 0.2 and $0.5 \mu \mathrm{m}$ correspond to agglomerates of these primary particles. As the

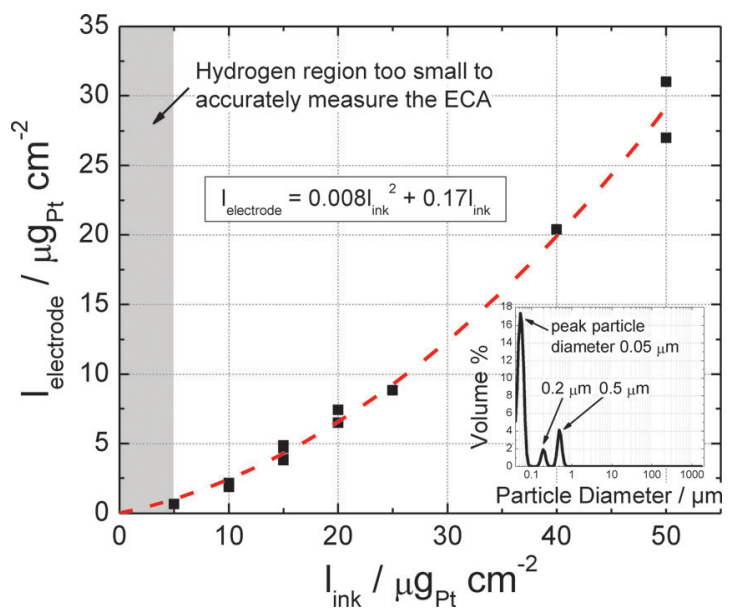

Fig. 2 Comparison of catalyst loading in the ink $\left(l_{\text {ink }}\right)$, before deposition and on the electrode ( electrode $_{\text {) }}$, after deposition. The dash line shows a parabolic fit with the equation $I_{\text {electrode }}=0.008 /_{\text {ink }}{ }^{2}+0.17 I_{\text {ink }}$. The inset shows a particle size analysis of the catalyst ink. 
loadings increased, the lost fraction was reduced (35\% loss for a loading of $30 \mu \mathrm{g}_{\mathrm{Pt}} \mathrm{cm}^{-2}$ ). This is believed to be because the larger agglomerates form on the surface and prevent the smaller particles from travelling down the pores. From the volume fractions determined above, it would appear that only the largest particles in the ink are captured by the filter at the lowest loadings. The collection efficiency should asymptotically approach $100 \%$ as the catalyst loading is increased. However, for the range of catalyst loadings in this study, a quadratic fit through the origin has been applied, to give a good approximation of the expected loading on the electrode $\left(l_{\text {electrode }}\right)$ from the quantity of catalyst in the ink $\left(l_{\text {ink }}\right)$, eqn (1).

$$
l_{\text {electrode }}=0.008 l_{\text {ink }}^{2}+0.17 l_{\text {ink }}
$$

The quantity of catalyst on the electrode was calculated from the electrochemically active surface area (ECA), measured from hydrogen adsorption (assuming $210 \mu \mathrm{C} \mathrm{cm}^{-2}$ ) and converted to a loading using the specific surface area of the platinum on the catalyst $\left(89 \mathrm{~m}^{2} \mathrm{~g}^{-1}\right) .{ }^{36}$ For electrodes with catalyst loadings of $<0.5 \mu \mathrm{g}_{\mathrm{Pt}} \mathrm{cm}^{-2}$, the hydrogen region became too small to accurately determine the ECA from CV data. Therefore, the catalyst values were predicted using the quadratic fit described above. Although the catalyst could anchor in the pores of the PCTE membrane upon deposition, no detrimental effects to the mass transport of reactant gas to the electrochemically active catalyst was visible, as discussed below. Catalyst loadings between 0.16 and $15 \mu \mathrm{g}_{\mathrm{Pt}} \mathrm{cm}^{-2}$ were produced. Once deposited, the electrodes were hotpressed at $140{ }^{\circ} \mathrm{C}$ and $6 \mathrm{MPa}$ for $240 \mathrm{~s}$ to cure the PFSA.

To protect against water build up and possible flooding within the pores of the gold-coated PCTEs acting as the GDL, a coating of an amorphous fluoropolymer (AF) (DuPont DeNemour, a copolymer of 2,2-bistrifluoromethyl-4,5,difluoro-1,3-dioxile and tetrafluoroethylene with the trade name Teflon AF 2400, $2.1 \mu \mathrm{g} \mathrm{cm}_{\text {Geo }}^{-2}$ dissolved in Fluorinert FC-40 (Sigma, F9755) was applied onto the bare side of the PCTE membranes. The electrodes were then dried for $1 \mathrm{~h}$ at $25 \mathrm{mbar}$ and $90{ }^{\circ} \mathrm{C}$ to remove residual solvents from the fabrication process. The AF is a hydrophobic polymer which is a substitute to PTFE. The application of the AF in its dissolved form meant a thin and uniform film was left after evaporation of the solvent, ${ }^{37}$ ideal for coating the $400 \mathrm{~nm}$ pores of the polycarbonate. This coating method also eliminates the sintering step at $>300{ }^{\circ} \mathrm{C}$, needed when applying the more typically used PTFE colloids, which would cause degradation of the PCTE membrane. Finally, the electrodes were stored in ultra pure water before characterization and electrochemical analysis.

\section{Substrate properties}

The permeabilities of the PCTE membranes were assessed by measuring flow (Sensidyne Gilibrator-2) as a function of pressure (Druck digital pressure indicator, DPI 705 IS) and applying Darcy's law. The contact angles of water on the AF coated membrane were measured using optical contact angle measurement with the static sessile drop method utilizing Fta32 V 2.0 contact angle software (First Ten Angstom Inc).
The drop was viewed through a digital camera (Phillips SPC900NC) at $20 \times$ magnification (Edmund Optics Infinity K2/S Long Distance Video Lens). The capillary pressure was tested experimentally by placing the hydrophobized PCTE membrane in a vacuum filtration setup with a water reservoir above; a vacuum was applied to create close to 1 atm (101 kPa) pressure drop across the membrane.

\section{Catalyst layer thickness and structure}

The catalyst layer was observed on the macro and micro scale with an optical microscope (Nikon Eclipse E600) using Nikon ACT software version 2.62 and a Gemini 1525 field emission gun scanning electron microscope (FEMSEM). Image analysis was performed with ImageJ V1.45s. The thickness of the catalyst layers were measured in two ways: A Zygo white light inferometer (NewView 7100, $2 \mathrm{~nm}$ depth resolution, 3-20 $\mu \mathrm{m}$ lateral resolution) with the Metro New View MicroErr.app software and AFM (Agilent Technologies, 5500) with a Nanosensor PPP-FM cantilever using Agilent Technologies PicoView software v1.8.2. In both techniques, the difference between the heights of the catalyst layer to the level of the PCTE membrane gave the thickness.

\section{Electrochemical measurements of the floating electrode}

All electrochemical measurements were carried out using a Gamry Reference 600 potentiostat. The WE was placed in contact with the aqueous electrolyte, Fig. 3. A Luggin capillary of $3 \mathrm{~mm}$ diameter was placed $5 \mathrm{~mm}$ from the working electrode, the distance chosen so as not to introduce shielding effects. ${ }^{38}$ Due to substantially higher currents produced for the ORR and HOR compared to the RDE, the standard $0.5 \mathrm{~mol} \mathrm{dm}^{-3}$ aqueous electrode concentration with a conductance of $0.18 \mathrm{~S} \mathrm{~cm}^{-1}$ (ref. 39) led to a significant uncompensated resistance between the working electrode and Luggin capillary reference electrode. Therefore, $4 \mathrm{~mol} \mathrm{dm}^{-3}$ perchloric acid

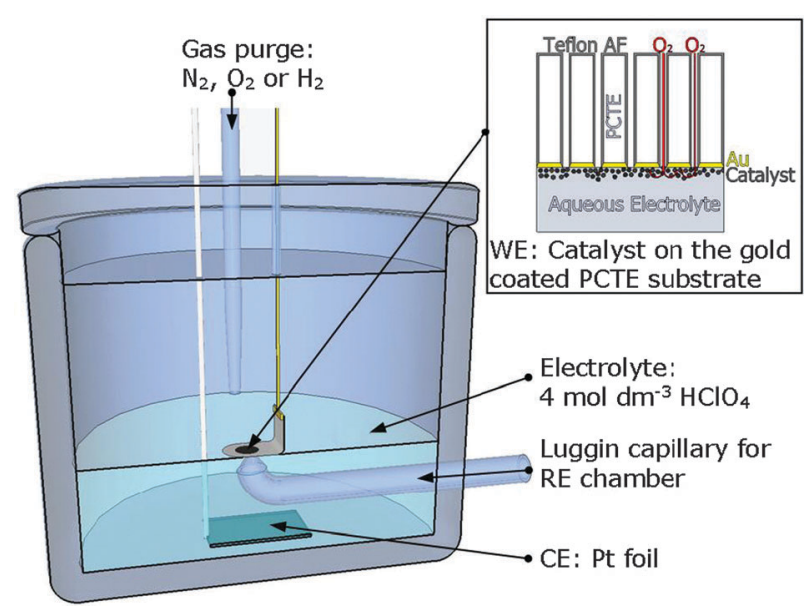

Fig. 3 A diagrammatic representation of the experimental setup, showing the working electrode floating on top of an aqueous electrolyte. This inset shows the structure of the working electrode, made up of catalyst deposited onto a gold coated porous PCTE membrane. The pores are coated with the hydrophobic AF to keep the pores open for reactant gas to flow to the catalyst from behind, in this case oxygen. 
(conductance of $0.74 \mathrm{~S} \mathrm{~cm}^{-1}$ ) was used in these experiments. No detrimental effects or change in features were observed in the more concentrated acid, except for the reduction in resistive losses. The reactant gas was blown onto the back of the electrode, where it could diffuse down the hydrophobic pores to the catalyst layer. The potential across the $\mathrm{WE}$ was scanned 10 times at $100 \mathrm{mV} \mathrm{s}^{-1}$ from 0 to $1.23 \mathrm{~V} v s$. RHE to electrochemically clean the electrodes before experiments. To analyze the double layer contribution of the substrate, $\mathrm{CO}$ adsorption was performed by holding the potential at $0.05 \mathrm{~V}$ vs. RHE for 15 minutes whilst blowing $\mathrm{CO}$ gas over the electrode. The solution was then purged with nitrogen before $\mathrm{CV}$ experiments were run. All experiments were carried out at room temperature and iR corrected using the high frequency intercept of the impedance at a range of voltages. Typical resistances varied between $0.1-0.15 \Omega \mathrm{cm}^{2}$. The current densities are expressed as either $\mathrm{mA} \mathrm{cm}^{-2}$ Spec or $\mathrm{mA} \mathrm{cm}{ }_{\text {Geo, }}^{-2}$ denoting specific $\left(j_{\text {spec }}\right.$ ) (or real, meaning per area active catalyst as determined via hydrogen underpotential adsorption measurements) and geometric $\left(j_{\mathrm{Geo}}\right)$ current densities, respectively.

\section{Results and discussion}

Fig. 4 shows SEM images of a $0.16 \mu \mathrm{g}_{\mathrm{Pt}} \mathrm{cm}^{-2}$ catalyst layer, on a gold coated porous polycarbonate substrate. The substrate has
$400 \mathrm{~nm}$ diameter pores, hydrophobized by the $\mathrm{AF}$ and a tortuosity of 1 . Furthermore, the catalyst particles preferentially deposited close to the pores at this catalyst loading, allowing for the optimum conditions depicted in Fig. 1. This optimum deposition geometry was achievable due to the VFC deposition technique. The inset in Fig. 3 provides a cartoon of the electrode configuration.

\section{Low loading catalyst layers}

The catalyst layer was deposited via VFC using the PCTE membrane as a filter. As the solvent was sucked through the pores, the catalyst was pulled to areas where vacant pores lie, making VFC a self-levelling technique, capable of spreading the catalyst evenly across the surface of the substrate. This is in contrast to solvent evaporation techniques, which typically produce a non-uniform catalyst distribution at very low loadings. The VFC technique is very simple and able to achieve reproducible and uniform catalyst layers over the entire deposition area $(0.2 \mathrm{~cm})$. Optical microscope (insets) and SEM images of catalyst loadings between $0.16-2.5 \mu_{\mathrm{Pt}} \mathrm{cm}^{-2}$ Geo, with thicknesses between 200-600 nm, are shown in Fig. 5 .

A repeatable spot size of $2 \pm 0.01 \mathrm{~mm}$ diameter was achievable with the VFC technique, with the spot size dependent on the mask chosen. The catalyst deposited uniformly across the

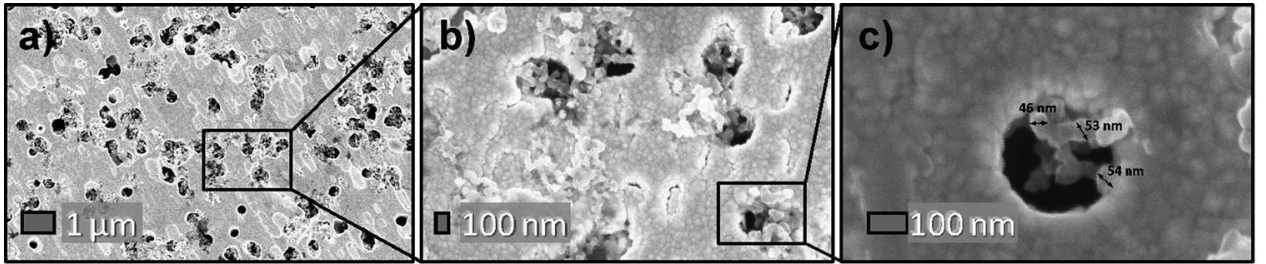

Fig. 4 SEM images of Pt/C catalyst agglomerates in the pores of a gold coated polycarbonate substrate at (a) $25 \mathrm{k} \times$, (b) $100 \mathrm{k} \times$ and (c) $300 \mathrm{k} \times$ magnification.

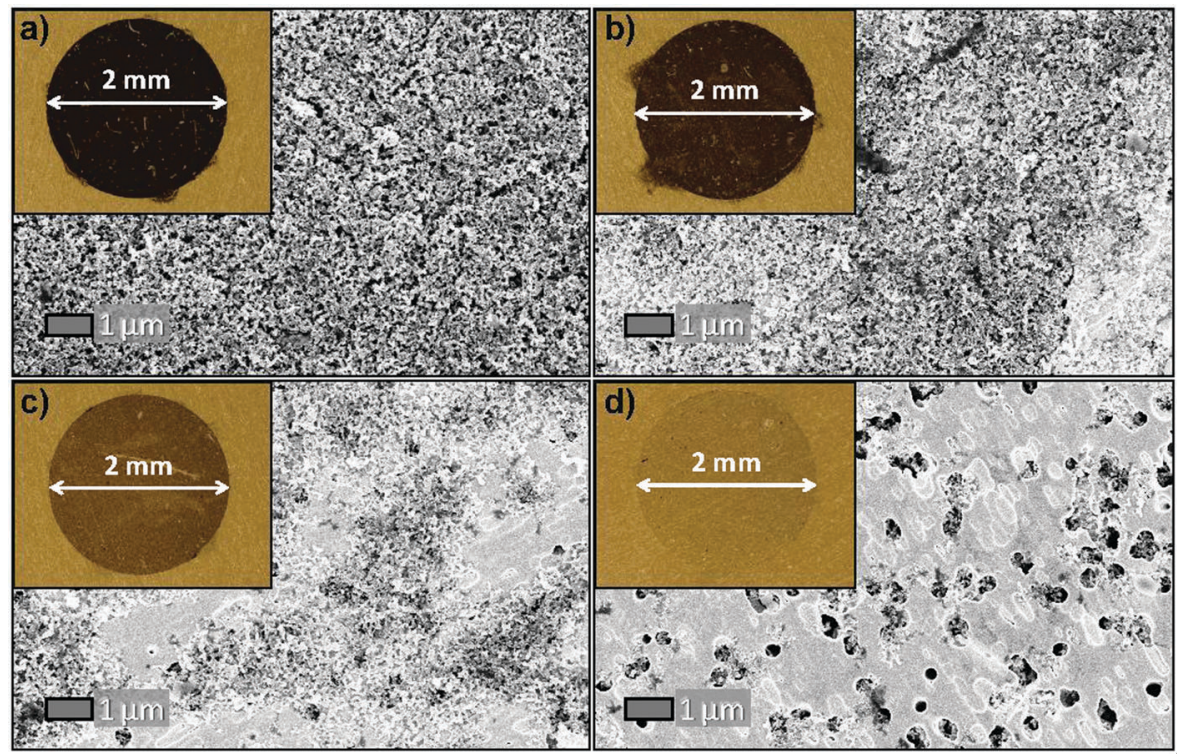

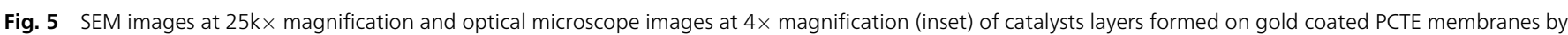
the VFC method. The catalyst loadings are: (a) $2.5 \mu \mathrm{g}_{\mathrm{pt}} \mathrm{cm}^{-2}$, taken to be one monolayer; (b) $1 \mu \mathrm{g}_{\mathrm{pt}} \mathrm{cm}^{-2}$; (c) $0.5 \mu \mathrm{g}_{\mathrm{pt}} \mathrm{cm}^{-2}$; and (d) $0.16 \mu \mathrm{g}_{\mathrm{pt}} \mathrm{cm}^{-2}$. 
entire deposition area, even at the ultra low loading of $0.16 \mu \mathrm{g}_{\mathrm{Pt}} \mathrm{cm}^{-2}$. This uniformity was attainable because of both the deposition procedure and the low roughness of the substrate (discussed below). A low roughness was needed to avoid the catalyst from preferentially depositing into the troughs, creating a non-uniform layer with varying thicknesses. VFC causes the catalyst to self level as it deposits onto the substrate surface, creating an ultra thin catalyst layer which can be as thin as $200 \mathrm{~nm}$ (measured by AFM). This avoided the typical coffee ring effect seen upon evaporation of the ink, when depositing low quantities of catalysts. ${ }^{10}$ The catalyst layers deposited via VFC were found to be significantly more reproducible with respect to morphology, thickness and size than we were able to achieve with the evaporation techniques such as the catalyst coated membrane (CCM) technique. A $60 \% \mathrm{Pt}$ on carbon support catalyst was chosen to reduce the amount of carbon in the catalyst layer, allowing for thinner layers with equivalent catalyst loading. As discussed in the introduction, reducing the thickness should diminish any concentration polarization within the catalyst layer, providing an ideal catalyst layer for measuring intrinsic catalyst properties. However, different platinum to carbon loadings could be studied using this technique. For a $20 \% \mathrm{Pt}$ on carbon support, the catalyst layer loading could be dropped by a factor of five for the same thickness.

At the microscopic level, the catalyst layers of 2.5, 1, 0.5 and $0.16 \mu \mathrm{g}_{\mathrm{Pt}} \mathrm{cm}^{-2}$, become less dense as the loading decreased. The $2.5 \mu \mathrm{g}_{\mathrm{Pt}} \mathrm{cm}^{-2}$ catalyst layer retained a complete film. For this reason we label this loading as a monolayer coverage. The 1 and $0.5 \mu \mathrm{g}_{\mathrm{Pt}} \mathrm{cm}^{-2}$ loadings formed incomplete layers, with gaps within the layer increasing as the loading is decreased. The $0.16 \mu \mathrm{g}_{\mathrm{Pt}} \mathrm{cm}^{-2}$ catalyst layer formed small clusters of catalyst around the pores, with vast spaces in between. Fig. 4 shows these clusters deposited around the pores, which is beneficial for supplying reactant gas to the catalyst. Therefore, it is evident that below $2.5 \mu \mathrm{g}_{\mathrm{Pt}} \mathrm{cm}^{-2}$, the catalyst layer reduced in density as well as thickness. This is believed to be because the thickness is determined by the size of the $\mathrm{Pt} / \mathrm{C}$ agglomerates in the ink; the size of the Pt/C agglomerates determines the minimum thickness and below a monolayer of these $\mathrm{Pt} / \mathrm{C}$ agglomerates, the agglomerates spread apart, rather than reduce in size.

\section{Parameters of the substrate}

The PCTE membrane was coated with a $100 \mathrm{~nm}$ layer of gold to provide a current collector. The gold coating can be seen in the optical microscope and SEM images of Fig. 4 and 5. The pores remain open after deposition, although the diameter decreases by half the deposition thickness, in this case by $50 \mathrm{~nm}$. The use of gold was motivated by its excellent electrical conductivity and chemical inertness; it is the third most conductive metal with an electrical resistivity of $2.21 \mu \Omega \mathrm{cm} .{ }^{40}$ This substrate also has a low surface roughness (RMS roughness $\leq 40 \mathrm{~nm}$, measured with AFM).

The hydrophobic layer of the AF was coated on the back of the PCTE membrane, preventing the aqueous electrolyte or condensate water from flooding the pores. In the cell, the

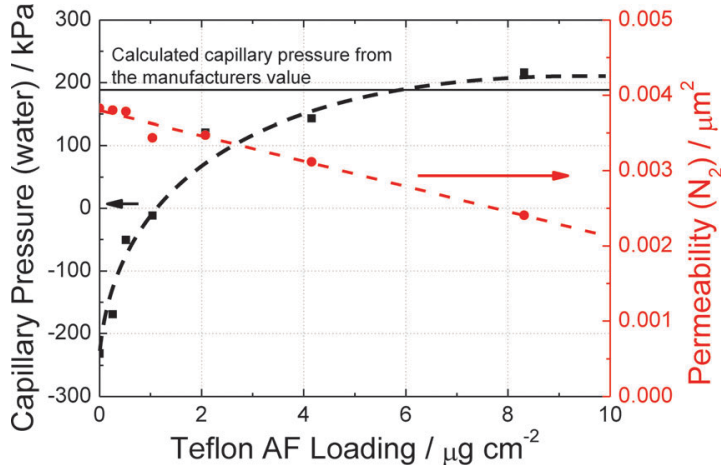

Fig. 6 Effect of the AF coating on the capillary pressure (water) and permeability $\left(\mathrm{N}_{2}\right)$ of the PCTE membrane.

hydrophobic layer caused the electrodes to float on-top of the aqueous electrolyte as illustrated in Fig. 3, leaving the pores open for reactant gas to travel through. However, care was taken not to block the pores with the AF. Fig. 6 shows the effect of the AF loading on the water capillary pressure (calculated from the contact angle and Young Laplace equation) and the permeability. As the AF loading increases, the capillary pressure sharply converges to the expected capillary pressure for the pure AF (calculated from the AF contact angle of $105^{\circ}$ ), ${ }^{41}$ while the permeability decreases linearly as the AF fills the pores. An optimum loading of AF was found at $2.1 \mu \mathrm{g} \mathrm{cm}^{-2}$ Geo, where the capillary pressure was high ( $c a .120 \mathrm{kPa}$ ) and the permeability was not greatly reduced $\left(0.0038 \mu \mathrm{m}^{2}\right.$ for the PCTE membrane, to $0.0035 \mu \mathrm{m}^{2}$ for the modified PCTE membrane). The membrane was experimentally confirmed to have a capillary pressure $>101 \mathrm{kPa}$ as no liquid leakage was seen when an attempt was made to suck water through the membrane under vacuum. Assuming the AF (density is $1.67 \mathrm{~g} \mathrm{~cm}^{-3}$ ) ${ }^{41}$ forms a continuous uniform layer over the surface and pores of the PCTE membrane (roughness factor of 13.4), this loading would amount to a layer of $0.92 \mathrm{~nm}$ thickness. The pore diameter would be reduced by less than $1 \%$.

To be a suitable GDL, the PCTE membrane must have high mass transport of the reactants and products, to reduce mass transport effects. To analyze the suitability of the PCTE membrane as a GDL, a flux for the PCTE membrane was calculated using Fick's first law, taking into account the porous PCTE membrane with an effective diffusion coefficient ( $\left.D_{\text {eff }}\right)$, eqn (2). ${ }^{42}$

$$
D_{\text {eff }}=\frac{\phi \delta}{\tau} D
$$

Where $D_{\text {eff }}$ was calculated from: the diffusion coefficient $(D)$, pore fraction $(\phi)$, constrictivity $(\delta)$ and tortuosity $(\tau)$. As the pores are $400 \mathrm{~nm}$, they have negligible constriction of the flow $(\delta=1)$. Fickian diffusion was assumed because the pore size is greater than the mean free path of hydrogen and oxygen at 126 and $74 \mathrm{~nm}\left(25{ }^{\circ} \mathrm{C}\right.$ and $\left.100 \mathrm{kPa}\right),{ }^{40}$ respectively. This gives a Knudsen number of 0.315 and 0.185 , for oxygen and hydrogen, respectively. The Knudsen number is defined as the ratio of the mean free path of the gas molecule to the system length scale, in this case the pore diameter. Knudsen diffusion only becomes 
influential when the Knudsen number is greater than 1. However, these PCTE membranes can be obtained with a range of pore sizes spanning both the Fickian and Knudsen diffusion regimes $(0.01-10 \mu \mathrm{m})$ and might be a useful approach to study constrained diffusion effects. Assuming the flow of oxygen and hydrogen within the pores is equivalent to the molecular diffusivity of the gas through air $\left(D=0.226 \mathrm{~cm}^{2} \mathrm{~s}^{-1}\right.$ for oxygen and $0.655 \mathrm{~cm}^{2} \mathrm{~s}^{-1}$ for hydrogen, at $\left.25{ }^{\circ} \mathrm{C}\right),{ }^{43}$ the $D_{\text {eff }}$ for oxygen and hydrogen through the polycarbonate membrane is 0.028 and $0.082 \mathrm{~cm}^{2} \mathrm{~s}^{-1}$, respectively. Under mass transport limiting conditions, a maximum current can be calculated using Faraday's Law, leading to a limiting current density of 448 and $650 \mathrm{~A} \mathrm{~cm}^{-2}$ Geo for oxygen and hydrogen, respectively. By comparison, air has a mass transport limiting current density of $90 \mathrm{~A} \mathrm{~cm}^{-2}$ Geo. It is realized that these values represent the diffusion properties of the PCTE membrane only; there will be an additional contribution to the limiting current density from diffusion of reactants through the catalyst layer. A full discussion of the electrodes diffusion properties is discussed with experimental results below.

\section{Electrochemistry of the catalyst layer}

Fig. 7 shows a CV of an electrode in nitrogen purged perchloric acid. The ECA of the catalyst was determined from hydrogen adsorption to be $0.42 \mathrm{~cm}^{2}$ over the $2 \mathrm{~mm}$ diameter spot size. This gave a loading of $15 \mu \mathrm{g}_{\mathrm{Pt}} \mathrm{cm}^{-2}$ since the known specific surface area of the platinum catalyst is $89 \mathrm{~m}^{2} \mathrm{~g}^{-1} \cdot{ }^{36}$ The inset in Fig. 7 is a photo of this electrode. The catalyst shows typical platinum features $^{32}$ as well as a large double layer. The hydrogen fine structure is visible, showing the anodic and cathodic peaks. The slight gradient in the oxide region and in the double layer region after $0.5 \mathrm{~V} v s$. RHE is likely to be oxidation of persistent organics accentuated by the lower currents of the ultra-low loadings of platinum. The disproportionately large charge of the double layer was found to be independent of the catalyst loading but characteristic of the gold layer from the substrate. As the catalyst loadings were low, the capacitance from the gold surface area became significant in the double

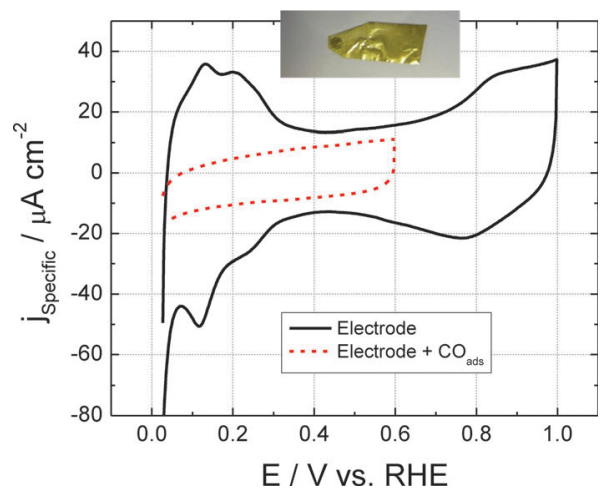

Fig. 7 Cyclic voltammogram of a $15 \mu \mathrm{g}_{\mathrm{Pt}} \mathrm{cm}^{-2} \mathrm{Pt} / \mathrm{C}$ catalyst layer on the gold coated PCTE substrate (photo at the top). Run in nitrogen purged $0.5 \mathrm{~mol} \mathrm{dm}^{-3}$ perchloric acid at a scan rate of $20 \mathrm{mV} \mathrm{s}^{-1}$. The dashed line shows a scan of the electrode up to $0.6 \mathrm{~V}$ vs. RHE after CO adsorption, rendering the Pt inactive. layer region. To show this, the electrode was exposed to $\mathrm{CO}$, the dash line in Fig. 7. The CO adsorbed on the Pt catalyst, de-activating its contribution to the overall double layer capacitance. This left the double layer to be a contribution of the gold substrate and carbon support. The scan was limited to $<0.6 \mathrm{~V} v s$. RHE to avoid CO oxidation at higher potentials.

\section{Oxygen reduction reaction}

Fig. 8 shows polarization curves of the ORR on a catalyst with a $4.9 \mu \mathrm{g}_{\mathrm{Pt}} \mathrm{cm}^{-2}$ loading (roughness factor of 4.3). The ORR was studied in $4 \mathrm{~mol} \mathrm{dm} \mathrm{dClO}_{4}$ at $10 \mathrm{mV} \mathrm{s}^{-1}$ scan rate. A maximum specific current density at $0.38 \mathrm{~V} v s$. RHE of $-185 \mathrm{~mA} \mathrm{~cm}^{-2}$ Spec was achieved, corresponding to a geometric

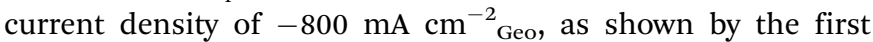
ordinate axis on the right. The second ordinate axis on the right shows the mass activity at $165 \mathrm{~A} \mathrm{mg}^{-1} \mathrm{Pt}$. The geometric current density is a two orders of magnitude improvement over the $\mathrm{RDE}$, which is limited by the low concentration and diffusion coefficient of oxygen through aqueous electrolytes as mentioned in the introduction. In this system, the same current densities were achieved regardless of whether the electrolyte was saturated with reactant gas or not (results not shown), revealing that the majority of the reactant gas travels to the catalyst through the PCTE pores.

The curve has a similar shape to ORR results with high mass transport electrodes reported in the literature. ${ }^{7,30,44}$ At $0.9 \mathrm{~V} v s$. RHE, the anodic scan has a current density of $0.282 \mathrm{~mA} \mathrm{~cm}^{-2}$ Spec, corresponding to a value of $0.25 \mathrm{~A} \mathrm{mg}^{-1} \mathrm{Pt}$. This value falls to the high end of the range of specific current densities at $0.9 \mathrm{~V} v s$. RHE previously reported ${ }^{7,45,46}$ for RDE and fuel cell apparatus after correcting for temperature (literature values are reported at $60{ }^{\circ} \mathrm{C}$, while this study was carried out at $25^{\circ} \mathrm{C}$ ). On the cathodic scan, the current density was reduced to $0.105 \mathrm{~mA} \mathrm{~cm}^{-2}$ Spec. The difference in the anodic and cathodic scan is known to occur

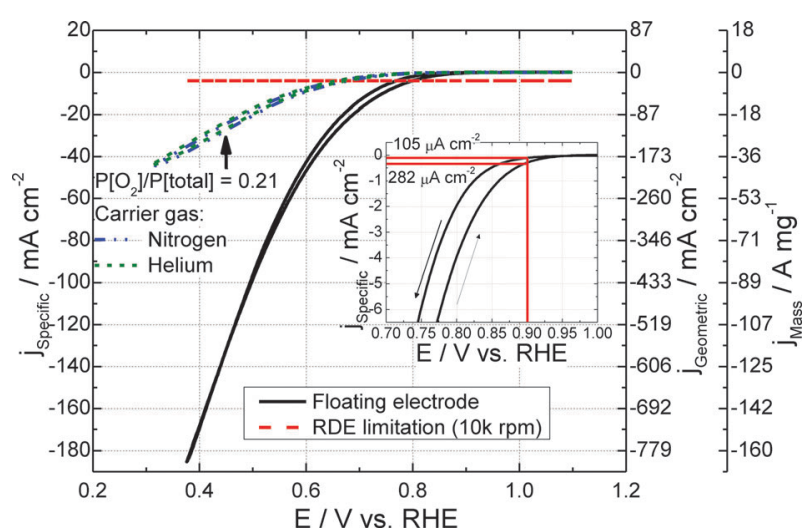

Fig. $84.9 \mu \mathrm{g}_{\mathrm{Pt}} \mathrm{cm}^{-2} \mathrm{Pt} / \mathrm{C}$ catalyst exposed to oxygen, run in $4 \mathrm{~mol} \mathrm{dm}{ }^{-3} \mathrm{HClO}_{4}$ at $10 \mathrm{mV} \mathrm{s}^{-1}$ at $298 \mathrm{~K} . \mathrm{CE}=\mathrm{Pt}, \mathrm{RE}=\mathrm{RHE}$. The dash line refers to the RDE limiting current density of $14 \mathrm{~mA} \mathrm{~cm}^{-2}$ Geo. Partial pressure measurements using nitrogen (dash dot line) or helium (short dash line) as the carrier gas are shown for $P\left[\mathrm{O}_{2}\right] / P[$ total $]=0.21$, synthetic air. The ordinate axis corresponds to the specific current density (left), geometric current density (first right) and mass activity (second right). The inset shows the curve between 0.7 and $1 \mathrm{~V}$ vs. RHE, with the activity at $0.9 \mathrm{~V} v$ s. RHE highlighted. 
due to an adsorption hysteresis of $\mathrm{OH}_{\mathrm{ads}}$, which acts as a competitor to oxygen adsorption, reducing the rate of ORR. ${ }^{46}$ The scan is curved for potentials above approximately $0.6 \mathrm{~V} v s$. RHE, showing that the electrode was mainly kinetically controlled across the cathode working conditions of a PEFC (0.6-0.8 V vs. RHE). This allows the performance of the electrode to be observed at $0.65 \mathrm{~V} v s$. RHE, a potential more relevant to fuel cell operation. For a range of catalyst loadings measured in this study (between 1.9 to $10.15 \mu_{\mathrm{Pt}} \mathrm{cm}^{-2}$, spanning sub monolayer and multilayer coverage of catalyst), the average current density was $31 \pm 9 \mathrm{~mA} \mathrm{~cm}{ }_{\text {Spec }}^{-2}\left(28 \pm 8 \mathrm{~A} \mathrm{mg}^{-1}{ }_{\mathrm{Pt}}\right)$ for the anodic scan. Below $0.6 \mathrm{~V}$ vs. RHE the voltammogram became somewhat linear. A more complete analysis of the ORR on these electrodes will be given in a following paper.

In comparison to $I-V$ curves of fuel cell data (assuming negligible losses from the HOR), the ORR mass activities observed in this technique exceed performance over the entire range of working potentials, even though the results reported in this paper are obtained at room temperature and ambient pressure. ${ }^{46,47}$ However, the curve followed a similar path to PEFC $I-V$ curves. For example, Gasteiger et al. ${ }^{46}$ presents an $I-V$ curve (Fig. 1 in ref. 46) with a current density of $\sim 0.2 \mathrm{~A} \mathrm{~cm}^{2}{ }_{\text {Geo }}$ $\left(\sim 0.5 \mathrm{~A} \mathrm{~cm}^{-2}\right.$ Geo after correcting for $\mathrm{iR}$ and mass transport losses) at $0.8 \mathrm{~V} v s$. RHE and a temperature of $80{ }^{\circ} \mathrm{C}$. With a cathode loading of $0.4 \mathrm{mg}_{\mathrm{Pt}} \mathrm{cm}^{-2}$, this corresponds to a mass activity of $1.25 \mathrm{~A} \mathrm{mg}^{-1}$ Pt. Using the technique reported here, we measure a mass activity of $4.3 \pm 1.2 \mathrm{~A} \mathrm{mg}^{-1}{ }_{\mathrm{Pt}}$ ), at a higher oxygen partial pressure $(101 \mathrm{kPa})$, but only $25{ }^{\circ} \mathrm{C}$. Correcting the result of Gasteiger et al. to an oxygen partial of $101 \mathrm{kPa}$, as to a first approximation the current density scales directly with the oxygen partial pressure, gives a mass activity of $4.2 \mathrm{~A} \mathrm{mg}^{-1} \mathrm{Pt}$, similar to our value but taken at a higher operating temperature.

\section{Hydrogen oxidation reaction}

Fig. 9 shows the HOR on a $2.2 \mu \mathrm{g}_{\mathrm{Pt}} \mathrm{cm}^{-2}$ loading (roughness factor of 1.9) in $4 \mathrm{~mol} \mathrm{dm}^{-3}$ perchloric acid at a scan rate of $10 \mathrm{mV} \mathrm{s}^{-1}$.

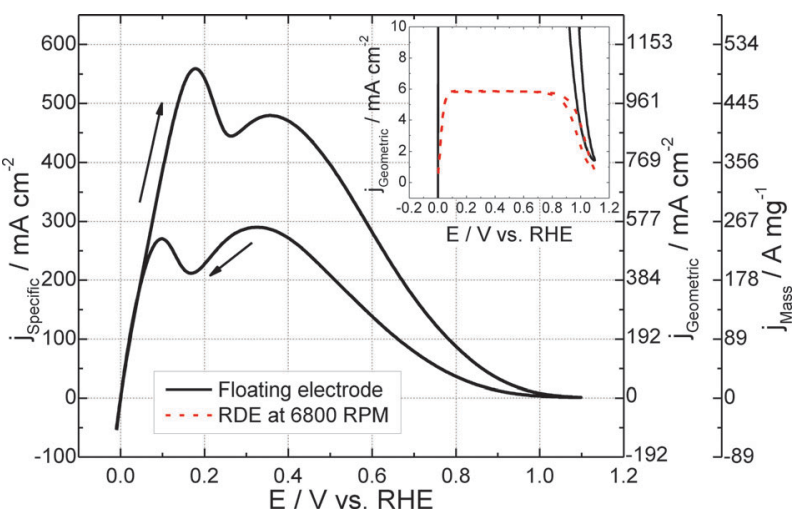

Fig. $92.2 \mu \mathrm{g}_{\mathrm{Pt}} \mathrm{cm}^{-2} \mathrm{Pt} / \mathrm{C}$ catalyst exposed to hydrogen, run in $4 \mathrm{~mol} \mathrm{dm}^{-3}$ $\mathrm{HClO}_{4}$ at $10 \mathrm{mV} \mathrm{s}^{-1}$ at $298 \mathrm{~K} . \mathrm{CE}=\mathrm{Pt}, \mathrm{RE}=\mathrm{RHE}$. The ordinate axis corresponds to the specific current density (left), geometric current density (first right) and mass activity (second right). The inset shows the HOR of Pt on a RDE in comparison to the floating electrode in terms of geometric current density. The RDE was rotated at $6800 \mathrm{rpm}$, in $0.5 \mathrm{~mol} \mathrm{dm}^{-3} \mathrm{HClO}_{4}$, at $10 \mathrm{mV} \mathrm{s}^{-1}$.

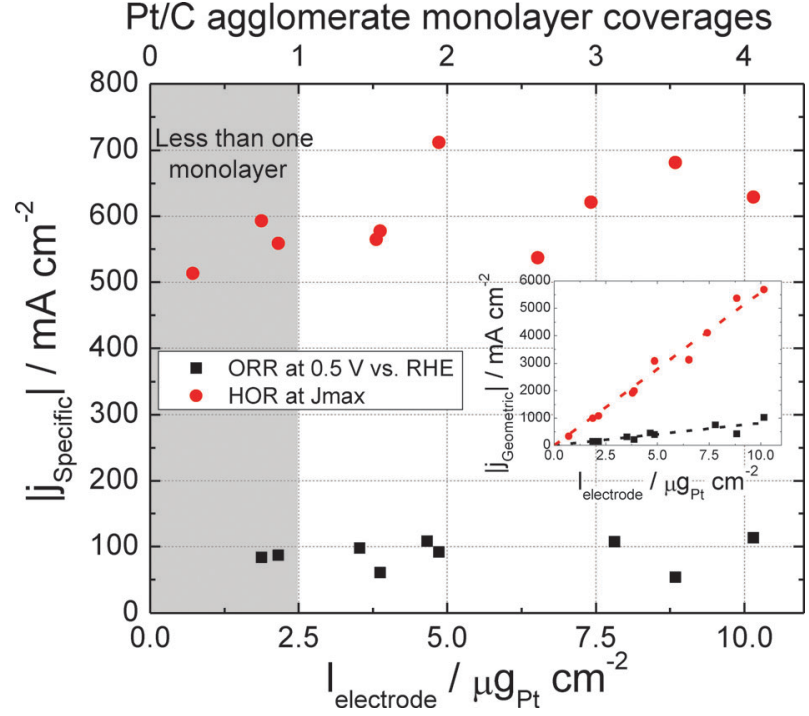

Fig. 10 Comparison of the normalised specific currents densities for the ORR at $0.5 \mathrm{~V}$ vs. RHE and HOR at the peak current for catalyst layers of different platinum loadings $\left(0.72-10.15 \mu \mathrm{g}_{\mathrm{Pt}} \mathrm{cm}^{-2}\right)$ at $298 \mathrm{~K}$. The inset shows the activity in terms of normalised geometric current densities.

Initially, the reaction rate increases rapidly to a maximum current density of $559 \mathrm{~mA} \mathrm{~cm}{ }^{-2}$ Spec at $0.18 \mathrm{~V}$ vs. RHE. This corresponded to a geometric current density of $1074 \mathrm{~mA} \mathrm{~cm}^{-2}$ Geo as shown by the first ordinate axis on the right. The second ordinate axis on the right shows the mass activity at $497 \mathrm{~A} \mathrm{mg}^{-1}$ Pt. Fig. 10 shows the relation of the maximum current density $\left(j_{\text {max,Spec }}\right)$ to the catalyst loading (between 0.72 to $10.15 \mu \mathrm{g}_{\mathrm{Pt}} \mathrm{cm}^{-2}$, spanning sub monolayer and multilayer coverage of catalyst), with an average maximum current density measured at $600 \pm 60 \mathrm{~mA} \mathrm{~cm}^{-2}$ spec. The inset in Fig. 10 shows a linear trend of geometric current density with a maximum current density of $5.7 \mathrm{~A} \mathrm{~cm}^{-2}$ Geo reached. However, a gradual increase in the potential of the peak was observed suggesting a mass transport resistance was shifting the peak to higher overpotentials; this effect will be discussed in a future paper.

Fine structure appeared in the hydrogen adsorption region $(0.18<\mathrm{V}$ vs. RHE $<0.36)$. This fine structure was observed before by Wesselmark et al. ${ }^{14}$ and attributed to adsorption of impurities. Fine structure observed on microelectrodes and the RDE, however, has been previously suggested as interaction of hydrogen adsorption with the $\mathrm{HOR}^{48,49}$ or different reaction rates for alternative HOR pathways. ${ }^{50}$ The different pathways include the Tafel-Volmer pathway (eqn (3) and (5)) and the Heyrovsky-Volmer pathway (eqn (4) and (5))

$$
\begin{array}{cc}
\mathrm{H}_{2}+\mathrm{Pt} \rightleftharpoons 2 \mathrm{Pt}-\mathrm{H}_{\mathrm{Chem}} & \text { Tafel reaction } \\
\mathrm{H}_{2}+\mathrm{Pt} \rightleftharpoons \mathrm{Pt}-\mathrm{H}_{\mathrm{Chem}}+\mathrm{H}^{+}+\mathrm{e}^{-} & \text {Heyrovsky reaction } \\
\mathrm{Pt}-\mathrm{H}_{\mathrm{Chem}} \rightleftharpoons \mathrm{Pt}+\mathrm{H}^{+}+\mathrm{e}^{-} & \text {Volmer reaction }
\end{array}
$$

Wang et al. ${ }^{50}$ suggested the Tafel-Volmer pathway dominates at small overpotentials, while the Heyrovsky-Volmer pathway gradually increase, taking over at $\eta=50 \mathrm{mV}$. In this study, the floating electrode allows gas to arrive directly to the 
back of the catalyst layer through hydrophobized pores, increasing mass transport to allow further resolution of the features in the hydrogen region. A discussion of the Tafel, Heyrovsky and Volmer contributions to the HOR will be discussed in a following paper on the kinetics of the HOR.

At potentials greater than $0.36 \mathrm{~V} v s$. RHE, the current decays asymptotically to $1.5 \mathrm{~mA} \mathrm{~cm}^{-2}$ Spec at $1.1 \mathrm{~V} v s$. RHE. The cause of this decrease has been previously explained as formation of oxides on the platinum surface ${ }^{51-53}$ and adsorption of anions. ${ }^{54}$ However, the onset of this current decay occurs before the oxide region shown in the CV in Fig. 7 (at $0.8 \mathrm{~V} v s$. RHE) and where the RDE has shown it to begin ( $>0.7 \mathrm{~V}$ vs. RHE). ${ }^{53}$ Although, with such a low limiting current density, the results collected from the RDE would not be able to resolve the beginning of this decay. This is highlighted in the inset of Fig. 9, showing a typical HOR curve at $6800 \mathrm{rpm}$, with the onset of the mass transport limiting current occurring at $<6 \mathrm{~mA} \mathrm{~cm}^{-2}$ Geo. The RDE signal is dominated by mass transport limitations between $100 \mathrm{mV}$ and $800 \mathrm{mV}$ vs. RHE. The fine structure in this voltage region only emerges if the experimental setup enables current densities of $\sim 600 \mathrm{~mA} \mathrm{~cm}{ }^{-2}$ spec.

A hysteresis above $0.1 \mathrm{~V} v s$. RHE is observed between the anodic and cathodic scans, with a peak current density of $559 \mathrm{~mA} \mathrm{~cm}{ }^{-2}$ Spec and $290 \mathrm{~mA} \mathrm{~cm}^{-2}$ Spec, respectively. This corresponds to a factor of two between the peak maximum of the anodic scan compared to the cathodic scan. Such a hysteresis has been observed at high potentials $(>0.7 \mathrm{~V} v s \text {. RHE })^{53}$ in low loading RDE experiments, although the complete effect is masked due to the effect of the low diffusion limited current on the RDE. ${ }^{50}$ For high mass transport systems, we have previously observed a hysteresis for the reverse scan. ${ }^{7}$ This hysteresis could be caused by hydrous oxide formation on the surface, ${ }^{55}$ anion adsorption effects or a mixture of both.

\section{Mass transport properties of the VFC electrodes}

To investigate the mass transport properties of the electrode, two diffusion profiles were evaluated; diffusion of reactants through the pores of the PCTE membrane, considered to be in the gas phase and diffusion of reactants from the pore to the catalyst reaction site. The diffusion through the catalyst layer is considered as either in the gas phase (through hydrophobic channels) or in the solution phase.

For the diffusion through the pores in the gas phase, the ORR was measured at an oxygen partial pressure over total pressure of 0.21 , with two different carrier gasses: nitrogen and helium; see the additional curves in Fig. 8. This technique has been previously used in PEFC's to measure diffusion characteristics. ${ }^{56}$ Oxygen diffusivity through helium is higher than nitrogen and therefore if gas diffusion is a limiting factor, an increase in performance should be visible with helium as the carrier gas. The curves overlap, showing negligible difference upon changing the carrier gas. Therefore, the PCTE membrane was considered free from mass transport effects, i.e. the diffusion of gas through the pores of the PCTE membrane was substantial enough to keep the partial pressure of oxygen at the gas/solution interface constant at the measured current densities. This was expected, as the calculated limiting current density from the PCTE membrane was two orders of magnitude greater at $448 \mathrm{~A} \mathrm{~cm}^{-2} \mathrm{Geo}$.

Assuming the catalyst layer was completely flooded, a semianalytical solution for the mass transport equation through the condensed phase was used to obtain an estimate for the impact of mass transport. As outlined in the appendix, the current density of the floating electrode $\left(j_{\text {fe }}\right)$ can be written as the product of a current density characterizing diffusion through the condensed phase $\left(j_{\text {cond }}\right)$ and a form factor:

$$
j_{\text {fe }}=j_{\text {cond }} F\left(\kappa, j_{\text {kin }}\right) \quad \text { with } j_{\text {cond }}=z F \frac{D_{\text {cond }} C_{0}}{r_{\mathrm{p}}}
$$

The characteristic current density $j_{\text {cond }}$ can be calculated from the reactant concentration $\left(c_{0}\right)$ in the condensed phase at the electrolyte-pore interface, half the average distance between pores $\left(r_{\mathrm{p}}\right)$, and the diffusion coefficient of the reactant gas in the condensed phase $\left(D_{\text {cond }}\right)$. The parameter $\kappa=r_{\mathrm{i}} / r_{\mathrm{p}}$ is given by the ratio of the pore diameter $r_{\mathrm{i}}$ over $r_{\mathrm{p}}$ and $j_{\text {kin }}$ represents the kinetic current density that would result if a constant concentration of $c_{0}$ would prevail in front of the electrode and the loss of catalytically active area due to noncatalyzed pores is neglected.

As stated above, the porous PCTE membranes used in our studies have a pore density of $10^{8}$ pores $\mathrm{cm}^{-2}$, which is equivalent to an average distance between pores of about $1.1 \mu \mathrm{m}$. A characteristic current density $j_{\text {cond }}$ of $0.21 \mathrm{~A} \mathrm{~cm}^{-2}$ $\left(0.14 \mathrm{~A} \mathrm{~cm}^{-2}\right)$ can be calculated for ORR (HOR) using standard values for the solubilities $\left(\mathrm{O}_{2}: 1.27 \times 10^{-3} \mathrm{~mol} \mathrm{dm}^{-3} ; \mathrm{H}_{2}: 0.78 \times\right.$ $\left.10^{-3} \mathrm{~mol} \mathrm{dm}^{-3}\right)$, diffusion coefficients $\left(\mathrm{O}_{2}: 2.42 \times 10^{-5} \mathrm{~cm}^{2} \mathrm{~s}^{-1}\right.$; $\mathrm{H}_{2}: 5.11 \times 10^{-5} \mathrm{~cm}^{2} \mathrm{~s}^{-1}$ ) in water at $25{ }^{\circ} \mathrm{C}$ (ref. 40) and $r_{\mathrm{p}}=$ $565 \mathrm{~nm}$. Note that this neglects salting-out effects. These values would give an indication of the limiting current density due to the condensed phase if diffusion would be planar over a length of $565 \mathrm{~nm}$ (half the average distance between pores). The geometric arrangement, however, is far from planar, which is expressed through the form factor.

As outlined in the appendix and shown in Fig. 11, this flooded catalyst layer arrangement would show a limiting current roughly equivalent to the characteristic current density $j_{\text {cond }}$ (electrolyte limited region in Fig. 11). However, current densities calculated from $j_{\text {cond }}$ are much lower than the current densities achieved by the floating electrode $\left(5.7 \mathrm{~A} \mathrm{~cm}^{-2}\right.$ Geo for the HOR), suggesting that the catalyst layers were not completely flooded. It is likely that the application of the AF after the deposition of the catalyst layer created hydrophobic channels, enabling distribution of reactants in the gaseous phase within the catalyst layer.

To distinguish the extent of mass transport effects, the current densities of the ORR at $0.5 \mathrm{~V} v s$. RHE (the linear region of the curve) and the HOR peak potential, were measured for a variety of catalyst loadings, from $0.72-10.15 \mu \mathrm{g}_{\mathrm{Pt}} \mathrm{cm}^{-2}$, Fig. 10 . This gave a range of geometric current densities between 0.14-1.02 $\mathrm{A} \mathrm{cm}_{\text {Geo }}^{-2}$ and 0.33-5.7 $\mathrm{A} \mathrm{cm}^{-2}$ Geo for the ORR and HOR, respectively. As the catalyst loading is increased, there is a requirement for more reactant to flow through the layer, and with a thicker layer, the reactant has to diffuse further through 


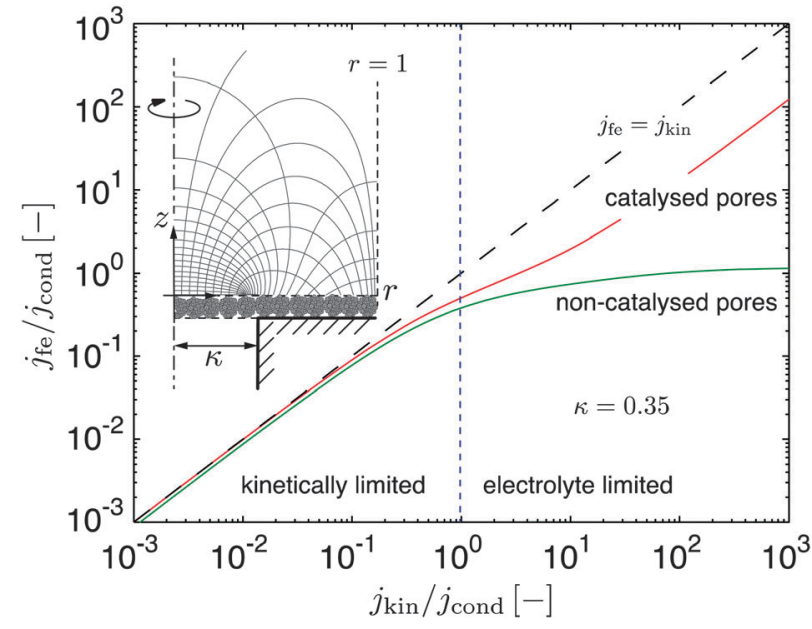

Fig. 11 Floating electrode current density as a function of the kinetic current density of the electrode; calculated for a ratio of pore radius to pore distance of $\kappa=0.35$; mass transport limitations due to the floating electrode arrangement are negligible as long as the kinetic current density is about one order of magnitude below the characteristic current density $j_{\text {cond }}$ defined by eqn (6).

the catalyst layer. Hence, any diffusion barrier to reactant flow would quickly become apparent as a reduction in specific activity for both the ORR and HOR. In the current range for studying the ORR $\left(\leq 1 \mathrm{~A} \mathrm{~cm}_{\text {Geo }}^{-2}\right)$ there was no apparent reduction in specific activity for catalyst loadings below $10.15 \mu \mathrm{g}_{\mathrm{Pt}} \mathrm{cm}^{-2}$, shown in Fig. 10, suggesting that the electrodes below this value do not significantly suffer from mass transport effects. The specific current density for the HOR peak potential remained constant. The peak potential, however, shifted with current density, suggesting some mass transport effects were present at the higher current densities $\left(\geq 1 \mathrm{~A} \mathrm{~cm}_{\text {Geo }}^{-2}\right.$.

Therefore, providing the ORR and HOR are operated in the

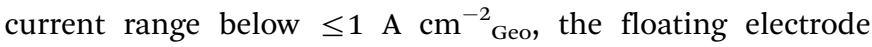
technique described in this paper provides a suitable method to avoid mass transport limitation at high potentials and therefore obtain intrinsic catalyst properties directly comparable to fuel cell data at high current densities.

\section{Conclusions}

VFC provides a simple method to deposit catalyst layers which were reproducible in size and uniform across the entire area. This reproducibility makes it a promising method for rapid and realistic parametric studies requiring different catalysts and catalyst layers. Although some of the catalyst was lost on deposition, this was accountable by measuring the ECA of the catalyst layer. Ultra-thin catalyst layers of $60 \% \mathrm{Pt}$ on carbon support were created down to a loading of $0.16 \mu \mathrm{g}_{\mathrm{Pt}} \mathrm{cm}^{-2}$ (a sub-monolayer of $\mathrm{Pt} / \mathrm{C}$ agglomerates), with a thickness of $200 \mathrm{~nm}$. At this thickness, internal resistance should be diminished, making an ideal catalyst layer for measuring intrinsic catalytic performance. Also, the need for only a small amount of catalyst makes it an ideal technique to measure novel catalysts, produced on the small scale. Further reduction in catalyst loading is possible by reducing the platinum loading on the carbon. For example, $20 \%$ Pt on carbon support would reduce the loading by a factor of five for an equivalent thickness.

Catalysts were deposited on gold coated, porous PCTE membranes. The AF was used to hydrophobize the pores. The coating caused the electrode to float on top of the aqueous electrolyte while keeping the pores free from flooding for gaseous transport of the reactants and products to and from the catalyst. Although the pore size used in this study was in the Fickian regime $(0.4 \mu \mathrm{m})$, membranes with smaller pore sizes would enable a parametric study across the Fickian/Knudsen regime.

The support had a calculated diffusion limited current of 448 and $650 \mathrm{~mA} \mathrm{~cm}^{-2}$ Geo for oxygen and hydrogen, respectively. Analysis of the support and catalyst layer, assuming the catalyst layer was flooded with aqueous electrolyte, showed theoretical mass transport limiting current densities of 0.21 and $0.14 \mathrm{~A} \mathrm{~cm}^{-2}$ Geo for oxygen and hydrogen, respectively. However, the experimentally achieved current densities were much higher (up to $5.7 \mathrm{~A} \mathrm{~cm}^{-2}$ Geo for the HOR), which we take as indication of fast gas-phase diffusion within the electrodes, possibly enabled by hydrophobic channels within the electrode introduced by the AF coating.

Cyclic voltammetry showed the PCTE membrane to be a suitable material to be used in PEFC/acidic conditions. For the ORR, a maximum current density of $185 \mathrm{~mA} \mathrm{~cm}{ }^{-2}$ spec or $800 \mathrm{~mA} \mathrm{~cm}^{-2}$ Geo was achieved at $0.38 \mathrm{~V} v s$. RHE for an electrode with a platinum loading of $4.9 \mu \mathrm{g}_{\mathrm{Pt}} \mathrm{cm}^{-2}$. At $0.9 \mathrm{~V} v s$. RHE, where a typical measurement in the RDE is made, the current density was $0.282 \mathrm{~mA} \mathrm{~cm}^{-2}$ Spec. Unlike the RDE, this electrode was not mass transport limited at current densities in PEFC relevant potentials (0.6-0.8 $\mathrm{V}$ vs. RHE), allowing a current density of $31 \pm 9 \mathrm{~mA} \mathrm{~cm}^{-2}$ spec at $0.65 \mathrm{~V} v$ s. RHE to be measured for a range of catalyst loadings. The profiles were comparable to PEFC data. The ORR performances, however, were found to exceed the $I-V$ curves for mass activity over the entire fuel cell range. The similar profiles demonstrate the techniques ability to accurately predict what the electrocatalytic performance would be in a PEFC. Mass transport effects for the ORR could not be observed from either the gas phase (from changing the carrier gas) or condensed phase (with no change in the specific current densities over a range of different catalyst loadings) for the catalyst loadings below $10.15 \mu \mathrm{g}_{\mathrm{Pt}} \mathrm{cm}^{-2}$, suggesting they are negligible.

For the HOR, a maximum specific current density of $600 \pm 60 \mathrm{~mA} \mathrm{~cm}{ }_{\text {Spec }}$, was measured for a range of catalyst loadings between 0.72 and $10.15 \mu \mathrm{g}_{\mathrm{Pt}} \mathrm{cm}^{-2}$. Hydrogen features were resolved, which could not be observed with the low mass transport rates of the RDE. The extra features include: fine structure of the HOR, a hysteresis effect between the anodic and cathodic scan, and a reduction in current before the oxide layer formation is typically considered to block the HOR. Further investigation into the features observed in the HOR will be published shortly along with further analysis of the ORR.

\section{Appendix}

The derivation of the form factor $F\left(\kappa, j_{\mathrm{kin}}\right)$ accounting for the geometry of the floating electrode arrangement in eqn (6) will 
be outlined below. $F\left(\kappa, j_{\text {kin }}\right)$ is obtained from a solution of the stationary diffusion equation

$$
\nabla^{2} c=0
$$

in the domain depicted in Fig. 11. We will work with dimensionless quantities by introducing the following transformations:

$$
r \rightarrow r / r_{\mathrm{p}}, \quad z \rightarrow z / r_{\mathrm{p}} \text { and } c \rightarrow c / c_{0}
$$

The ansatz

$$
c(r, z)=\sum_{n=0}^{\infty} C_{n} \exp \left(-\gamma_{n} z\right) J_{0}\left(\gamma_{n} r\right)
$$

satisfies eqn (A.1) in cylinder coordinates. Eqn (A.2) also ensures a vanishing concentration at infinite distances from the electrode for $\gamma_{n}>0$ and rotational symmetry at $r=0$. The boundary condition of a vanishing gradient at a distance $r=1$ is satisfied by constraining $\gamma_{n}$. Because

$$
\left.\partial_{r} J_{0}\left(\gamma_{n} r\right)\right|_{r=1}=-\gamma_{n} J_{1}\left(\gamma_{n}\right)=0
$$

only roots of the second Bessel function of the first kind are admissible values of $\gamma_{n}$.

The expansion coefficients $C_{n}$ have to be obtained from the boundary condition at $z=0$. It is useful to define the characteristic current density

$$
j_{\text {cond }}=z F \frac{c_{0} D_{\text {cond }}}{r_{\mathrm{p}}},
$$

because it allows to write the two conditions that apply at $z=0$ compactly as:

$$
\begin{gathered}
c(r, 0)=1 \text { for } 0<r<\kappa \\
j_{\text {kin }} c(r, 0)=-\left.j_{\text {cond }} \partial_{z} c(r, z)\right|_{z=0} \text { for } \kappa \leq r<1
\end{gathered}
$$

Eqn (A.4) simply ensures a homogeneous concentration over the pore. Boundary condition (A.5) expressed the flux conservation at the electrode-electrolyte interface and is valid for first order reactions such as the ORR and HOR, assuming that only one reactant concentration varies and that mass transport limitations are negligible within the electrode itself. Being first order, the Faradaic reaction will scale linearly with concentration, where the kinetic current density $j_{\text {kin }}$ would be achieved if the reference concentration $c_{0}$ would prevail in front of the electrode. The righthand side of eqn (A.5) simply expresses diffusive mass transport towards the electrode at the electrolyte-facing side of the interface. Introduction of the ansatz (A.2) into the mixed boundary condition (A.4) and (A.5) leads to the dual algebraic equation:

$$
\begin{gathered}
0=1-\sum_{n=0}^{\infty} C_{n} J_{0}\left(\gamma_{n} r\right) \quad \text { for } 0<r<\kappa \\
0=\sum_{n=0}^{\infty} C_{n}\left(1-\gamma_{n} j_{\text {cond }} / j_{\text {kin }}\right) J_{0}\left(\gamma_{n} r\right) \quad \text { for } \kappa \leq r<1
\end{gathered}
$$

Any set $\left\{C_{n}\right\}$ has to fulfill both equations simultaneously within the respective domain. Problems of this type are analytically solvable using another series expansion for the coefficients $C_{n}$, constructed in a way that either of the two boundary conditions is automatically satisfied. The resulting equations, however, tend to be very involved and usually bring no significant practical advantage over directly solving for $\left\{C_{n}\right\}$ numerically, because many terms of the series need to be evaluated before the series can be truncated. We, therefore, decided to use a numerical scheme to solve for $\left\{C_{n}\right\}$. The boundary at $z=0$ was subdivided into $N$ equally spaced intervals and (A.6) and (A.7) evaluated at these discrete points. The resulting linear system of $N$ equations is easily solved using standard linear algebra techniques, giving the first $N$ coefficients $C_{n}$ of eqn (A.2).

The current density of the floating electrode $j_{\mathrm{fe}}$ is found from integrating the diffusive flux at $z=0$ over the pore area, using Faraday's law, and multiplying with the pore density $\rho_{\text {pore }}=1$ / $\left(\pi r_{p}^{2}\right)$, which yields

$$
j_{\text {fe }}=j_{\text {cond }} \underbrace{2 \sum_{n=0}^{\infty} C_{n} \kappa J_{1}\left(\gamma_{n} \kappa\right)}_{=F\left(\kappa, j_{\text {kin }}\right)} .
$$

By defining $F\left(\kappa, j_{\text {kin }}\right)$ according to eqn (A.8), this can be written more compactly as eqn (6).

The behavior of the floating electrode arrangement as a function of the characteristics of the electrode is shown in Fig. 11 for two cases: (1) assuming a non-catalyzed pore area and (2) catalyst-covered pores. Note that eqn (A.8) has to be corrected by adding $\kappa^{2} j_{\text {kin }}$ to account for the catalyst pore area. The current density resulting for the floating electrode $j_{\mathrm{fe}}$ is shown as a function of the kinetic current density of the electrode $j_{\text {kin }}$. If $j_{\text {kin }}$ is significantly smaller than the characteristic current density $j_{\text {cond }}$, the geometry of the floating electrode arrangement becomes negligible and $j_{\text {fe }}$ equals $j_{\text {kin }}$ if the pore area is catalyzed. A correction for the non-catalyzed pore area (i.e., $j_{\mathrm{fe}}=j_{\mathrm{kin}}\left(1-\kappa^{2}\right)$ is needed otherwise. If operating conditions are chosen where the kinetic current density $j_{\text {kin }}$ would significantly exceed $j_{\text {cond }}$, mass transport through the electrolyte becomes rate limiting and a limiting current of the floating electrode roughly equal to the characteristic current density can be expected if no catalyst covers the pores. No limiting current behavior is observed if the pores are catalyzed, because catalyst in this area has direct access to the reactants. However, only the area over the pores will be active in the limiting case (i.e., $j_{\mathrm{fe}}=j_{\mathrm{kin}} \kappa^{2}$ ).

\section{Acknowledgements}

The authors would like to thank the EPSRC for funding the project through EP/G030995/1 - Supergen Fuel Cell Consortium Fuel cells - Powering a Greener Future - CORE. Also to David Anthony for taking the SEM pictures and Hiroshi Iden for his expertise on the RDE.

\section{Notes and references}

1 M. S. Wilson and S. Gottesfeld, J. Appl. Electrochem., 1992, 22, 1-7.

2 K. J. J. Mayrhofer, D. Strmcnik, B. B. Blizanac, V. Stamenkovic, M. Arenz and N. M. Markovic, Electrochim. Acta, 2008, 53, 3181-3188. 
3 Y. Sun, J. Lu and L. Zhuang, Electrochim. Acta, 2010, 55, 844-850. 4 A. Damjanovic, in Modern Aspects of Electrochemistry, ed. J. O. M. Bockris and B. E. Conway, Plenum Press, New York, 1969, vol. 5, pp. 369-483.

5 M. R. Tarasevich, A. Sadkowski and E. Yeager, in Comprehensive Treatise of Electrochemistry, ed. B. E. Conway, J. O. M. Bockris, E. Yeager, S. U. M. Khan and R. E. White, Plenum, New York, London, 1983, vol. 7, pp. 301-398.

6 T. J. Schmidt, H. A. Gasteiger, G. D. Stab, P. M. Urban, D. M. Kolb and R. J. Behm, J. Electrochem. Soc., 1998, 145, 2354-2358.

7 A. R. Kucernak and E. Toyoda, Electrochem. Commun., 2008, 10, 1728-1731.

8 J. Jiang and A. Kucernak, J. Electroanal. Chem., 2004, 567, 123-137.

9 J. Jiang and A. Kucernak, J. Electroanal. Chem., 2005, 576, 223-236.

10 R. D. Deegan, O. Bakajin, T. F. Dupont, G. Huber, S. R. Nagel and T. A. Witten, Nature, 1997, 389, 827-829.

11 E. A. Ticianelli, C. R. Derouin, A. Redondo and S. Srinivasan, J. Electrochem. Soc., 1988, 135, 2209-2214.

12 S. Mukerjee and S. Srinivasan, J. Electroanal. Chem., 1993, 357, 201-224.

13 K. C. Neyerlin, W. Gu, J. Jorne and H. A. Gasteiger, J. Electrochem. Soc., 2006, 153, A1955-A1963.

14 M. Wesselmark, B. Wickman, C. Lagergren and G. Lindbergh, Electrochem. Commun., 2010, 12, 1585-1588.

15 N. P. Subramanian, T. Greszler, J. Zhang, W. Gu and R. R. Makharia, ECS Trans., 2011, 41, 985-1007.

16 S. S. Kocha, J. Deliang Yang and J. S. Yi, AIChE J., 2006, 52, 1916-1925.

17 Z. Liu, J. S. Wainright, W. Huang and R. F. Savinell, Electrochim. Acta, 2004, 49, 923-935.

18 J. H. Ohs, U. Sauter, S. Maass and D. Stolten, J. Electrochem. Soc., 2012, 159, F181-F186.

19 H. Kuhn, B. Andreaus, A. Wokaun and G. G. Scherer, Electrochim. Acta, 2006, 51, 1622-1628.

20 J. Zhang, D. Kramer, R. Shimoi, Y. Ono, E. Lehmann, A. Wokaun, K. Shinohara and G. G. Scherer, Electrochim. Acta, 2006, 51, 2715-2727.

21 M. Reum, S. A. Freunberger, A. Wokaun and F. N. Büchi, J. Electrochem. Soc., 2009, 156, B301-B310.

22 L. G. Austin and S. Almaula, J. Electrochem. Soc., 1967, 114, 927-933.

23 J. Giner, J. M. Parry, S. Smith and M. Turchan, J. Electrochem. Soc., 1969, 116, 1692-1696.

24 H. R. Kunz and G. A. Gruver, J. Electrochem. Soc., 1975, 122, 1279-1287.

25 T. Maoka, Electrochim. Acta, 1988, 33, 371-377.

26 P. Björnbom, Electrochim. Acta, 1987, 32, 115-119.

27 J. Giner and C. Hunter, J. Electrochem. Soc., 1969, 116, 1124-1130.

28 B. V. Tilak, R. S. Yeo and S. Srinivasan, in Comprehensive Treatise of Electrochemistry, ed. J. O. M. Bockris, B. E. Conway, E. Yeager and P. E. White, Plenum Press, New York, 1981, vol. 3.

29 E. Antolini, L. Giorgi, A. Pozio and E. Passalacqua, J. Power Sources, 1999, 77, 136-142.
30 Y.-X. Chen, M.-F. Li, L.-W. Liao, J. Xu and S. Ye, Electrochem. Commun., 2009, 11, 1434-1436.

31 A. Kloke, S. Kerzenmacher, R. Zengerle and F. von Stetten, Solid-State Sensors, Actuators and Microsystems Conference, 2009. Transducers 2009. International , 2009.

32 B. E. Conway, H. Angerstein-Kozlowska, W. B. A. Sharp and E. E. Criddle, Anal. Chem., 1973, 45, 1331-1336.

33 J. E. Mark, Polymer Data Handbook, Oxford University Press, New York, 1999.

34 M. Uchida, Y. Aoyama, N. Eda and A. Ohta, J. Electrochem. Soc., 1995, 142, 463-468.

35 M. Uchida, Y. Fukuoka, Y. Sugawara, H. Ohara and A. Ohta, J. Electrochem. Soc., 1998, 145, 3708-3713.

36 Correspondence with Johnson Matthey Fuel Cells, 16 Dec 2009.

37 F. Bidault and A. Kucernak, J. Power Sources, 2011, 196, 4950-4956.

38 Southampton Electrochemistry Group, Instrumental Methods In Electrochemistry, Horwood Publishing, Chichester, 2006.

39 E. W. Washburn, in International Critical Tables of Numerical Data, Physics, Chemistry and Technology, (1st Electronic Edition), Knovel, 2003, pp. 1926-1930.

40 D. R. Lide, Handbook of Chemistry and Physics, CRC press, Boca Raton, 84th edn, 2004.

41 DuPont $^{\mathrm{TM}}$, Teflon ${ }^{\circledR}$ AF Amorphous Fluoropolymers H-44587-4 (01/10) http://www2.dupont.com/Teflon_Industrial/en_US/ assets/downloads/h44587.pdf (Accessed 10/10/2011).

42 P. Grathwohl, Diffusion in natural porous media: contaminant transport, sorption/desorption and dissolution kinetics, Kluwer Academic Publishers, Boston, 1998.

43 C. L. Yaws, Yaws, Handbook of Thermodynamic and Physical Properties of Chemical Compounds, Knovel, 2003.

44 W.-k. Paik, T. E. Springer and S. Srinivasan, J. Electrochem. Soc., 1989, 136, 644-649.

45 U. A. Paulus, T. J. Schmidt, H. A. Gasteiger and R. J. Behm, J. Electroanal. Chem., 2001, 495, 134-145.

46 H. A. Gasteiger, S. S. Kocha, B. Sompalli and F. T. Wagner, Appl. Catal., B, 2005, 56, 9-35.

47 J.-H. Wee, K.-Y. Lee and S. H. Kim, J. Power Sources, 2007, 165, 667-677.

48 N. M. Marković, S. T. Sarraf, H. A. Gasteiger and P. N. Ross, J. Chem. Soc., Faraday Trans., 1996, 92, 3719-3725.

49 S. Chen and A. Kucernak, J. Phys. Chem. B, 2004, 108, 13984-13994.

50 J. X. Wang, T. E. Springer and R. R. Adzic, J. Electrochem. Soc., 2006, 153, A1732-A1740.

51 K. Jambunathan, B. C. Shah, J. L. Hudson and A. C. Hillier, J. Electroanal. Chem., 2001, 500, 279-289.

52 J. Jiang and A. Kucernak, J. Electroanal. Chem., 2004, 567, 123-137.

53 G. K. H. Wiberg and M. Arenz, J. Power Sources, 2012, 217, 262-267.

54 S. Gottesfeld, I. D. Raistrick and S. Srinivasan, J. Electrochem. Soc., 1987, 134, 1455-1462.

55 L. D. Burke and J. A. Morrissey, J. Appl. Electrochem., 1996, 26, 593-601.

56 Y. W. Rho, O. A. Velev, S. Srinivasan and Y. T. Kho, J. Electrochem. Soc., 1994, 141, 2084-2089. 